Case Report

\title{
Ectopic Oral Tonsillar Tissue: A Case Series with Bilateral and Solitary Presentations and a Review of the Literature
}

\author{
Masashi Kimura, ${ }^{1}$ Toru Nagao, ${ }^{2}$ Terumi Saito, ${ }^{2}$ Saman Warnakulasuriya, ${ }^{3}$ \\ Hiroyuki Ohto, ${ }^{1}$ Akihito Takahashi, ${ }^{2}$ Kanji Komaki, ${ }^{4}$ and Yoshiyuki Naganawa ${ }^{1}$ \\ ${ }^{1}$ Department of Dentistry Oral and Maxillofacial Surgery, Ogaki Municipal Hospital, 4-86 Minaminokawa, Ogaki, \\ Gifu 503-8502, Japan \\ ${ }^{2}$ Department of Oral and Maxillofacial Surgery and Stomatology, Okazaki City Hospital, 3-1 Goshoai, Koryuji-cho, \\ Okazaki, Aichi 444-8553, Japan \\ ${ }^{3}$ Department of Oral Medicine, King's College London Dental Institute, WHO Collaborating Centre for Oral cancer/Precancer, \\ Bessemer Road, London SE5 9RS, UK \\ ${ }^{4}$ Department of Oral and Maxillofacial Surgery, Yokkaichi Municipal Hospital, Yokkaichi, Mie 510-8567, Japan
}

Correspondence should be addressed to Toru Nagao; tnagao@topaz.ocn.ne.jp

Received 4 December 2014; Accepted 22 December 2014

Academic Editor: Pablo I. Varela-Centelles

Copyright (C) 2015 Masashi Kimura et al. This is an open access article distributed under the Creative Commons Attribution License, which permits unrestricted use, distribution, and reproduction in any medium, provided the original work is properly cited.

\begin{abstract}
An ectopic tonsil is defined as tonsillar tissue that develops in areas outside of the four major tonsil groups: the palatine, lingual, pharyngeal, and tubal tonsils. The occurrence of tonsillar tissue in the oral cavity in ectopic locations, its prevalence, and its developmental mechanisms that belong to its formation remain unclear. In this report, we describe a rare case of bilateral symmetric ectopic oral tonsillar tissue located at the ventral surface of the tongue along with two solitary cases arising from the floor of the mouth. The role of immune system and its aberrant response leading to ectopic deposits desires further studies. As an ectopic tonsil may simulate a benign soft tissue tumor, this case series highlights the importance of this entity in our clinical differential diagnosis of oral soft tissue masses.
\end{abstract}

\section{Introduction}

The tonsils form part of a circular band of adenoid tissue known as Waldeyer's ring, which guard the opening of the digestive and respiratory tracts. This circular band is comprised of four major tonsil groups: the palatine, lingual, pharyngeal, and tubal tonsils. An ectopic tonsil is tonsillar tissue that develops in areas outside of these regions. The existence of ectopic oral tonsils was described by Knapp in 1970 [1]. It was shown that such structures, resembling pharyngeal and other tonsils, can be found within the oral cavity.

Ectopic tonsils have been reported in different anatomic locations of the oral cavity, for example, on the floor of the mouth [1-6], ventral surface of the tongue $[1,2,4]$, and soft palate $[1,2]$, and in other parts of the aerodigestive tracts, for example, larynx [7], hypopharynx [8], nasal septum [9], or in the orbit [10] (Table 1). Collection of tonsillar tissue in ectopic sites can cause diagnostic confusion; however, none of the reported cases have been described with a bilateral presentation and/or symmetrically such as that found in the oropharynx.

Here we report a rare case of bilateral symmetric ectopic oral tonsillar tissue observed on the ventral surface of the tongue and two other solitary cases arising from floor of the mouth along with a review of the literature.

\section{Case Presentations}

2.1. Case 1. A 53-year-old Japanese male, referred by his general dental practitioner, presented with small, bilaterally symmetric masses on the ventral surface of the tongue, noticed during a routine dental examination 2 months ago. The areas affected were painless and remained unchanged in size over the previous 2 months. Intraoral examination revealed hard masses of $8 \mathrm{~mm}$ diameter (right) and $6 \mathrm{~mm}$ 


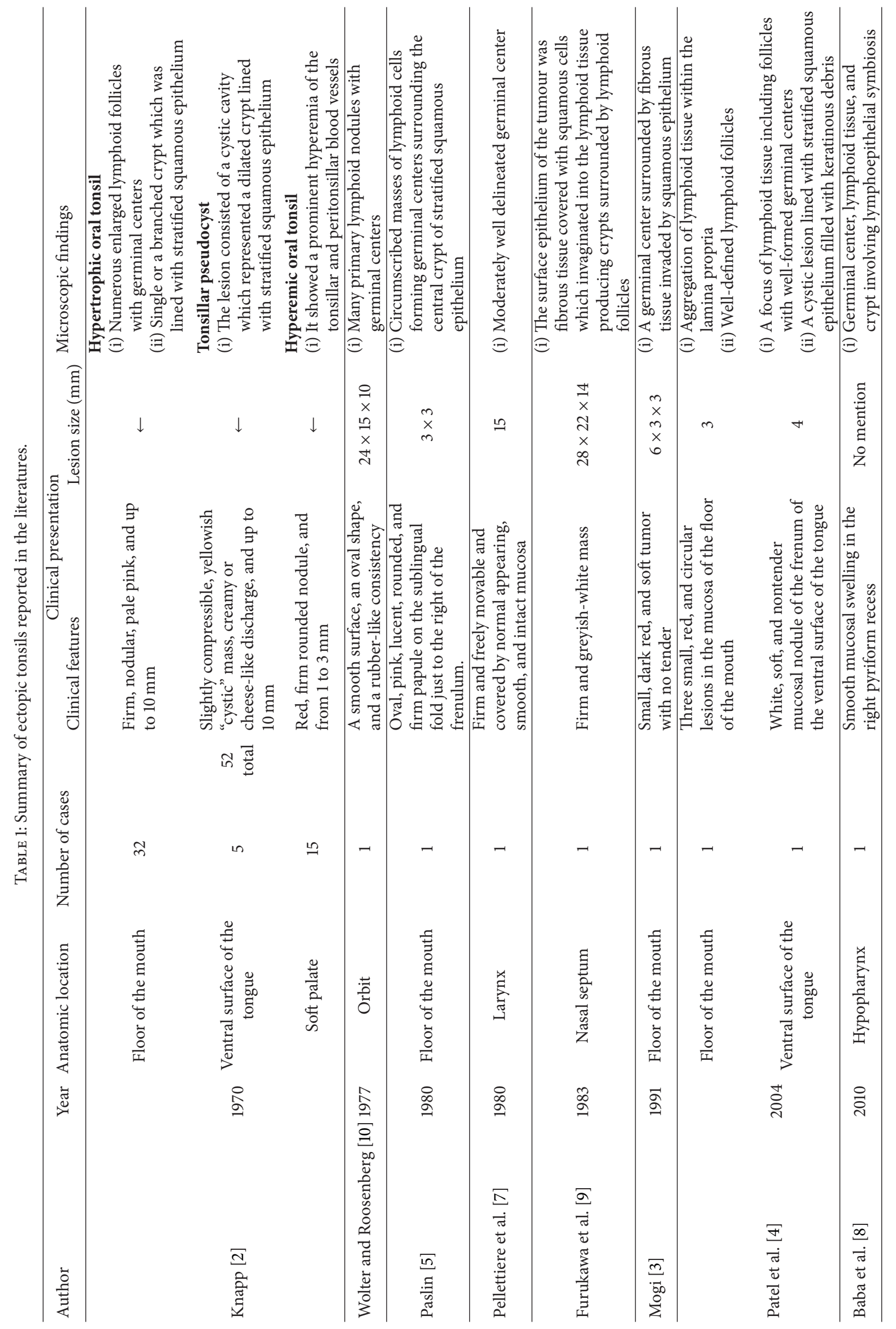




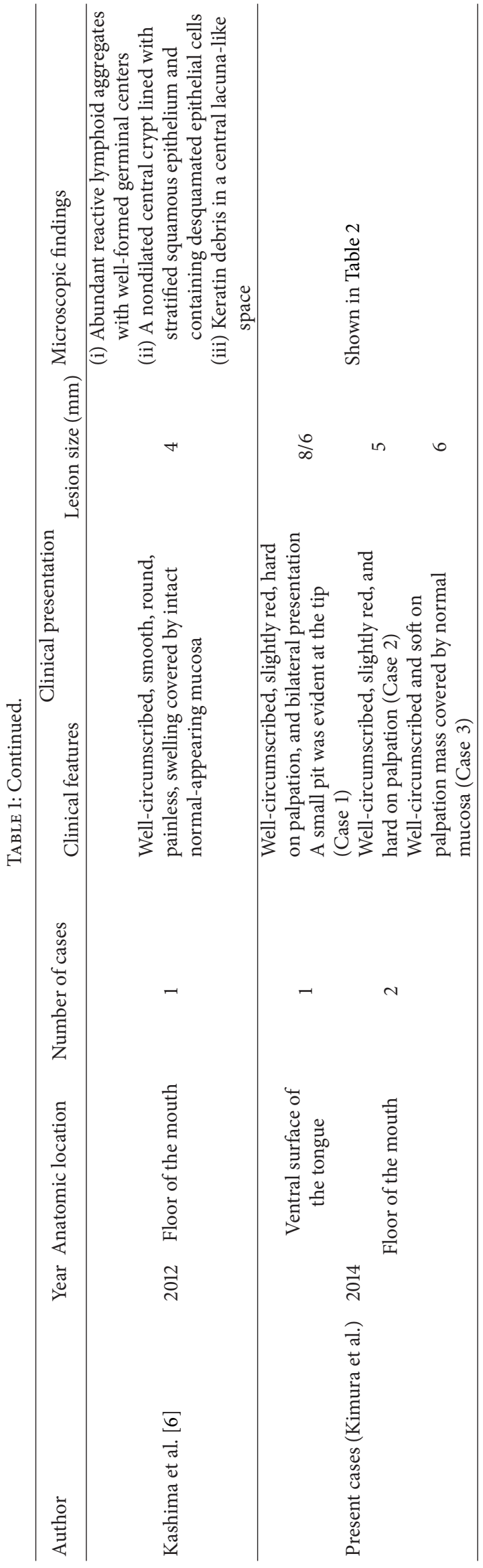


TABLE 2: Clinicopathological characteristics of three cases of ectopic tonsils.

\begin{tabular}{|c|c|c|c|}
\hline & \multicolumn{3}{|c|}{ Case number } \\
\hline & 1 & 2 & 3 \\
\hline Gender & Male & Female & Female \\
\hline Age & 53 & 63 & 38 \\
\hline Localization & Ventral surface of the tongue & Floor of the mouth & Floor of the mouth \\
\hline Number of lesions & Bilateral & Solitary & Solitary \\
\hline Lesion size $(\mathrm{mm})$ & $8 / 6$ & 5 & 6 \\
\hline Color of oral mucosa & Slightly red & Slightly red & Normal \\
\hline Palpation & Hard & Hard & Soft \\
\hline Clinical diagnosis & Benign salivary tumor & Benign salivary tumor & Mucocele \\
\hline \multicolumn{4}{|l|}{ Histopathological findings } \\
\hline Crypt architecture & + & + & + \\
\hline Encapsulation & + & + & + \\
\hline Lymphoepithelial symbioses & + & + & + \\
\hline Lymphoid follicle & + & + & + \\
\hline Crypt obstruction & - & - & - \\
\hline Cyst formation & - & - & - \\
\hline
\end{tabular}

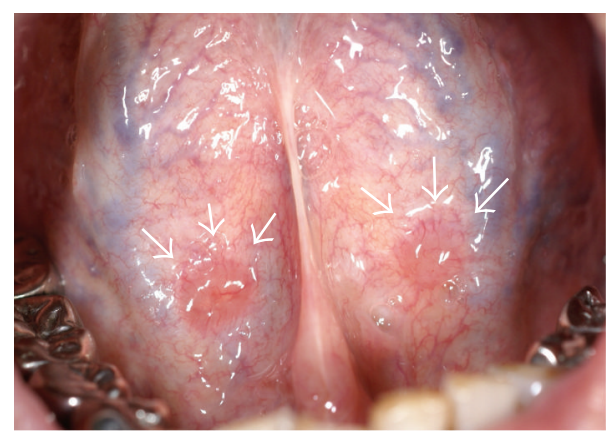

Figure 1: Clinical findings of Case 1. Small, bilaterally symmetric masses on the ventral surface of the tongue (arrows).

diameter (left) on the ventral surface of the tongue (Figure 1). The surface covering of these masses was slightly red and was hard on palpation. Clinically, a small pit was evident at the tip of both masses; a provisional diagnosis of bilateral benign tumors of salivary origin was made. An excision biopsy of the mass on the right side was subsequently performed under local anesthesia. The mass was easily resected and the postoperative course was uneventful. Histopathological findings showed a germinal center, lymphoid tissue, and lymphoepithelial symbiosis in the crypt (Figure 2). Although the bilateral symmetric ectopic oral tonsillar tissue arising from this region has not been reported elsewhere to our knowledge, clinicopathological characteristics were similar to two other cases (Cases 2 and 3) of solitary origin presented later in our clinic (Table 2).

2.2. Case 2. A 63-year-old Japanese female presented at our hospital with a small swelling on the left side of the floor of the mouth. She first noticed this lump 10 days previously. The affected area was painless and its size remained unchanged. Intraoral examination revealed a well-circumscribed mass
( $5 \mathrm{~mm}$ diameter) on the left side of the floor of the mouth (Figure 3). The mass was slightly red and hard on palpation and was clinically diagnosed as a benign salivary tumor of the floor of the mouth. It was resected under local anesthesia and at excision was found to be encapsulated and appeared fairly close to the sublingual salivary gland. However, it was completely detached from the gland by its own capsule. The postoperative course was uneventful. Histopathology revealed characteristic features of a tonsil with a germinal center, a mass of lymphoid tissue, and a crypt with lymphoepithelial symbiosis. These findings were suggestive of ectopic tonsillar tissue (Table 2).

2.3. Case 3. A 38-year-old Japanese female visited our clinic complaining of a small painless lump on the right side of the floor of the mouth. She first noticed this lesion 2 days ago. Intraoral examination revealed a well-circumscribed mass ( $6 \mathrm{~mm}$ diameter) covered by intact normal-appearing mucosa (Figure 4). The mass was soft on palpation and was clinically diagnosed as a mucocele of the floor of the mouth. It was resected under local anesthesia and at excision it was completely detached from the sublingual salivary gland and Wharton's duct by its own capsule. The postoperative course was uneventful. Pathological characteristics were similar to the earlier described cases (Table 2).

\section{Discussion}

Ectopic tonsils are comprised of a single or branched crypts containing lymphoid follicles lined with stratified squamous epithelium. In Table 1, we present single cases and case series of ectopic tonsils. A literature search was conducted in August 2014 using the electronic databases PubMed and Scopus and hand-searching using the search term of ectopic tonsil. The search was restricted to published articles containing clinicopathological features. Furthermore, search parameter 


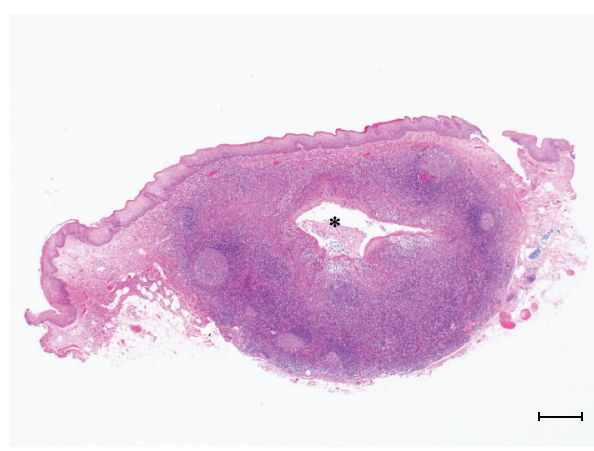

(a)

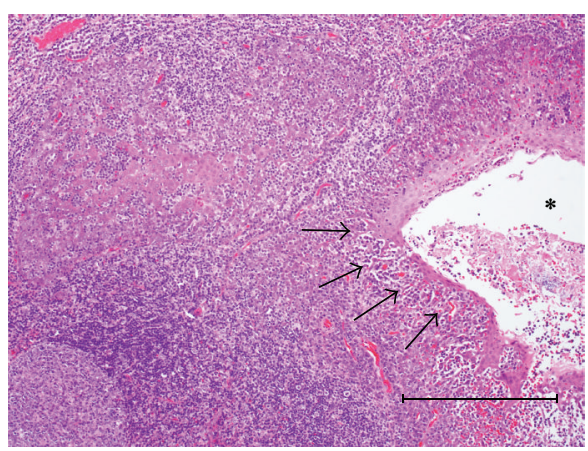

(b)

FIGURE 2: (a) Histopathological findings of Case 1. Germinal center, lymphoid tissue, and a crypt $\left(^{*}\right)$ are seen (Hematoxylin-Eosin (HE), scale bar $=250 \mu \mathrm{m})$. (b) Lymphoepithelial symbiosis in the crypt is seen (arrows) (HE, scale bar $=250 \mu \mathrm{m})$.

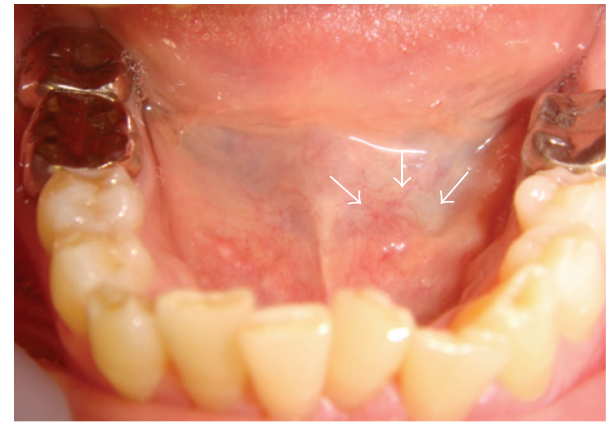

Figure 3: Clinical findings of Case 2. A small mass on the left side of the floor of the mouth (arrows). The mass was slightly red.

was also set to select literature restricted to English language only.

As a result only 62 cases have been reported in the English language. The most frequently affected area is the floor of the mouth (59\% of cases), followed by the soft palate $(24.6 \%)$ and ventral surface of the tongue $(9.8 \%)$. In the clinical findings, the size of the lesions ranged from 3 to $28 \mathrm{~mm}$ with rounded shape, and the surface covering of the lesions was occasionally and slightly red. Therefore, they may cause diagnostic confusion, especially when found around the floor of the mouth. It may be misdiagnosed as tumors that arise from the sublingual gland.

According to Knapp, lymphoepithelial cyst that originates from lymphoid tissue following obstruction of these crypts also may have similar presentation. Clinically, these lesions appear yellowish and comprise a cystic cavity that appears as a dilated crypt lined with a stratified squamous epithelium [2]. In the three cases presented here, although several serial sections of the specimens were examined, there was no evidence of cyst formation or crypt obstruction. On the basis of these histopathological findings, the authors diagnosed these masses as ectopic tonsils. According to Patel et al. [4] inflamed ectopic tonsils may swell and become tender, thus requiring resection. Usually, however, ectopic oral tonsils remain asymptomatic and can be left untreated, but surgical exploration is indicated to establish a tissue diagnosis [4]. In

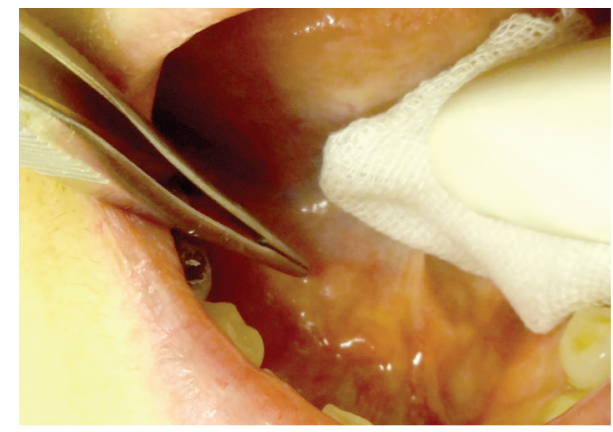

FIgURE 4: Clinical findings of Case 3. A small mass covered by intact normal-appearing mucosa on the right side of the floor of the mouth.

Case 1, excisional biopsy of one mass led to a histopathological diagnosis of ectopic tonsillar tissue. Thus, the need for surgical resection of the contralateral lesion was avoided.

The pathogenesis of ectopic tonsils in this region remains unclear. Lymphoid tissue is also found in fetal salivary glands, and occasionally remnants of lymphoid tissue are found in adult salivary glands [11]. The masses in Cases 2 and 3 appeared close to the sublingual gland but were completely separated from the salivary tissues, whereas the masses in Case 1 were placed distant from the salivary tissues, and thus the origins of these masses remained obscure. It is reported that ectopic tonsillar tissue in the nasal septum may result from persistent infection [9]. However, in Case 1, because the masses were bilateral and symmetrical, the etiology was not considered to be reactive lymphoid hyperplasia.

These cases reported by us highlight the possibility of ectopic oral tonsillar tissue and raise the need to consider them when making a differential diagnosis of soft tissue lumps found on the floor of the mouth and/or the ventral surface of the tongue. Further cadaveric study is required to clarify the presence of ectopic tonsillar tissue on these anatomical sites, particularly with regard to its developmental mechanisms, and to assess its prevalence and to study the clinical significance of the immune system and its response. 
Ectopic tonsils appear to occur more frequently than are generally recognized, probably because they are usually asymptomatic and are thus easily overlooked. We have described these three cases of ectopic tonsils to propose that clinicians may consider inclusion of this entity in the clinical differential diagnosis, often not encountered in reference text books in oral medicine and pathology.

\section{Conflict of Interests}

The authors declare that there is no conflict of interests regarding the publication of this paper.

\section{Acknowledgment}

The authors would like to thank Enago (http://www.enago .jp/) for the English language review.

\section{References}

[1] M. J. Knapp, "Oral tonsils: location, distribution, and histology," Oral Surgery, Oral Medicine, Oral Pathology, vol. 29, no. 1, pp. 155-161, 1970.

[2] M. J. Knapp, "Pathology of oral tonsils," Oral Surgery, Oral Medicine, Oral Pathology, vol. 29, no. 2, pp. 295-304, 1970.

[3] K. Mogi, "Ectopic tonsillar tissue in the mucosa of the floor of the mouth simulating a benign tumour. Case report," Australian Dental Journal, vol. 36, no. 6, pp. 456-458, 1991.

[4] K. Patel, S. Ariyaratnam, P. Sloan, and M. N. Pemberton, "Oral tonsils (ectopic oral tonsillar tissue)," Dental update, vol. 31, no. 5, pp. 291-292, 2004

[5] D. A. Paslin, "Accessory tonsils," Archives of Dermatology, vol. 116, no. 6, pp. 720-721, 1980.

[6] K. Kashima, K. Takamori, K. Igawa, I. Yoshioka, and S. Sakoda, "Oral tonsil in the floor of mouth: ectopic oral tonsillar tissue simulating benign neoplasms," Oral Science International, vol. 9, no. 1, pp. 29-31, 2012.

[7] E. V. Pellettiere II, L. D. Holinger, and J. A. Schild, "Lymphoid hyperplasia of larynx simulating neoplasia," Annals of Otology, Rhinology \& Laryngology, vol. 89, no. 1, part 1, pp. 65-68, 1980.

[8] Y. Baba, Y. Kato, and K. Ogawa, "Hyperplasia of lymphoid structures in the hypopharynx: a case report," Journal of Medical Case Reports, vol. 4, article 388, 2010.

[9] M. Furukawa, S. Takeuchi, and R. Umeda, "Ectopic tonsillar tissue in the nasal septum," Auris Nasus Larynx, vol. 10, no. 1, pp. 37-41, 1983.

[10] J. R. Wolter and R. J. Roosenberg, "Ectopic lymph node of the orbit simulating a lacrimal gland tumor," American Journal of Ophthalmology, vol. 83, no. 6, pp. 908-914, 1977.

[11] R. A. Colby, D. A. Kerr, and H. B. G. Robinson, Color Atlas of Oral Pathology, JB Lippincott, Philadelphia, Pa, USA, 2nd edition, 1961. 


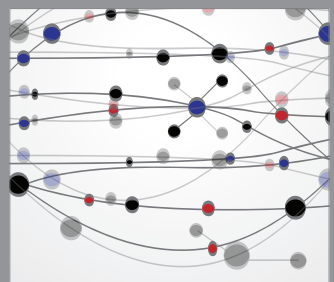

The Scientific World Journal
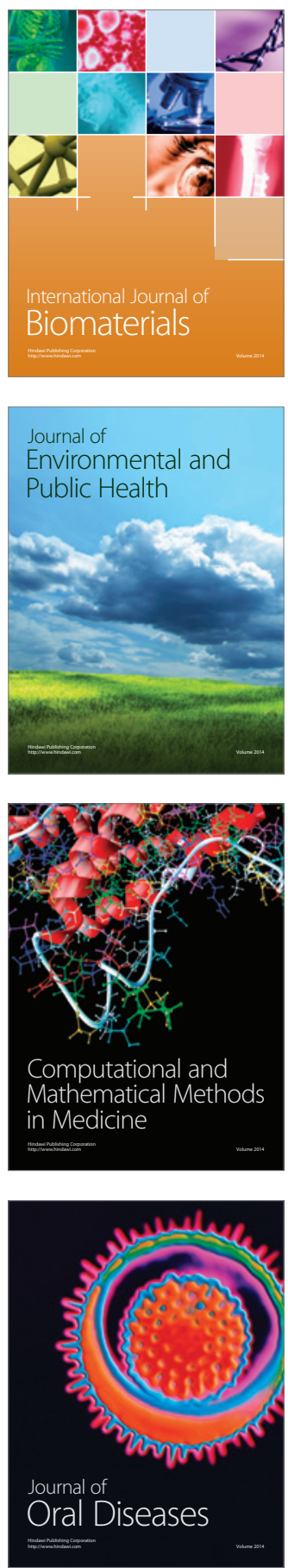
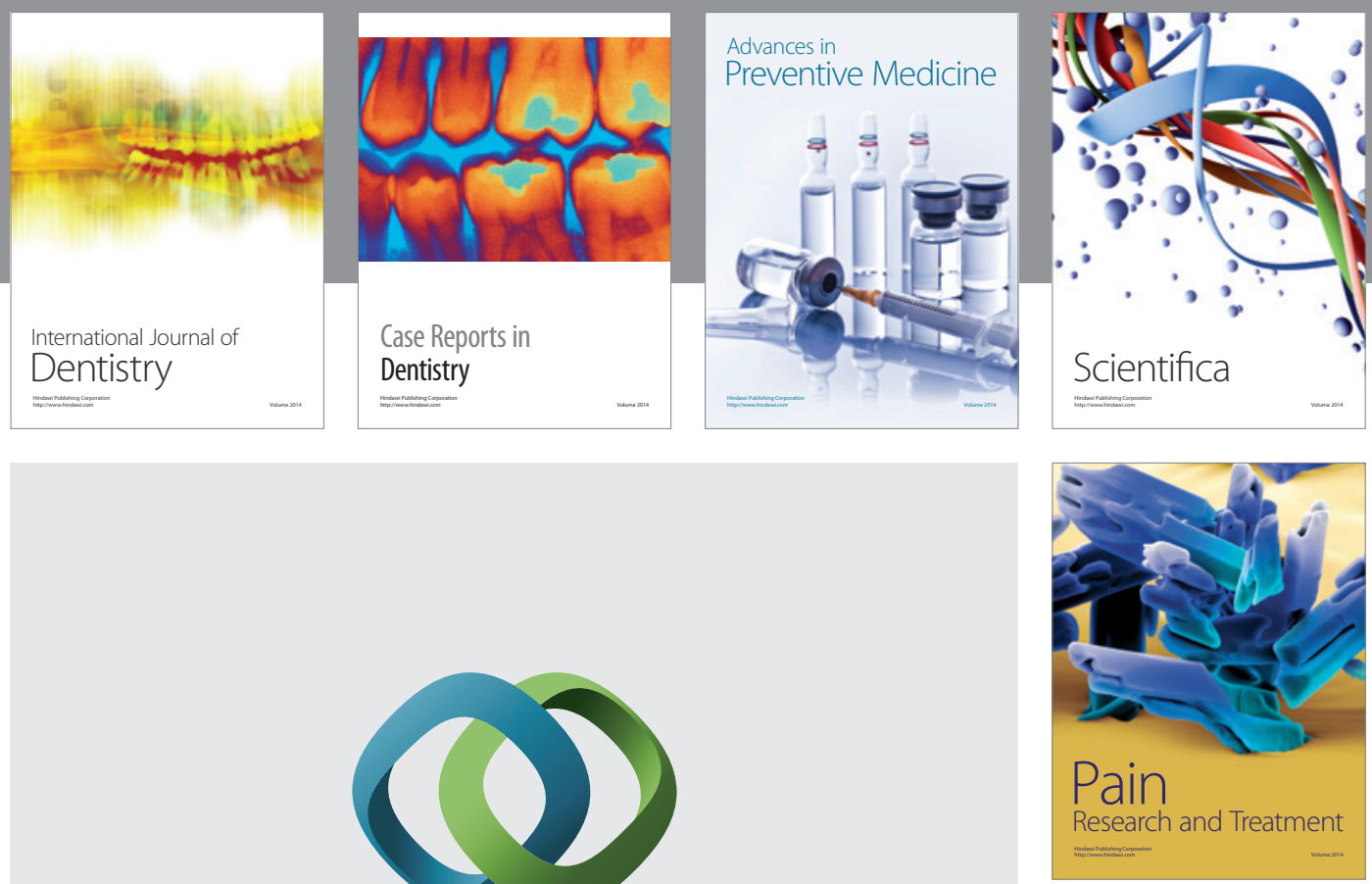

\section{Hindawi}

Submit your manuscripts at

http://www.hindawi.com
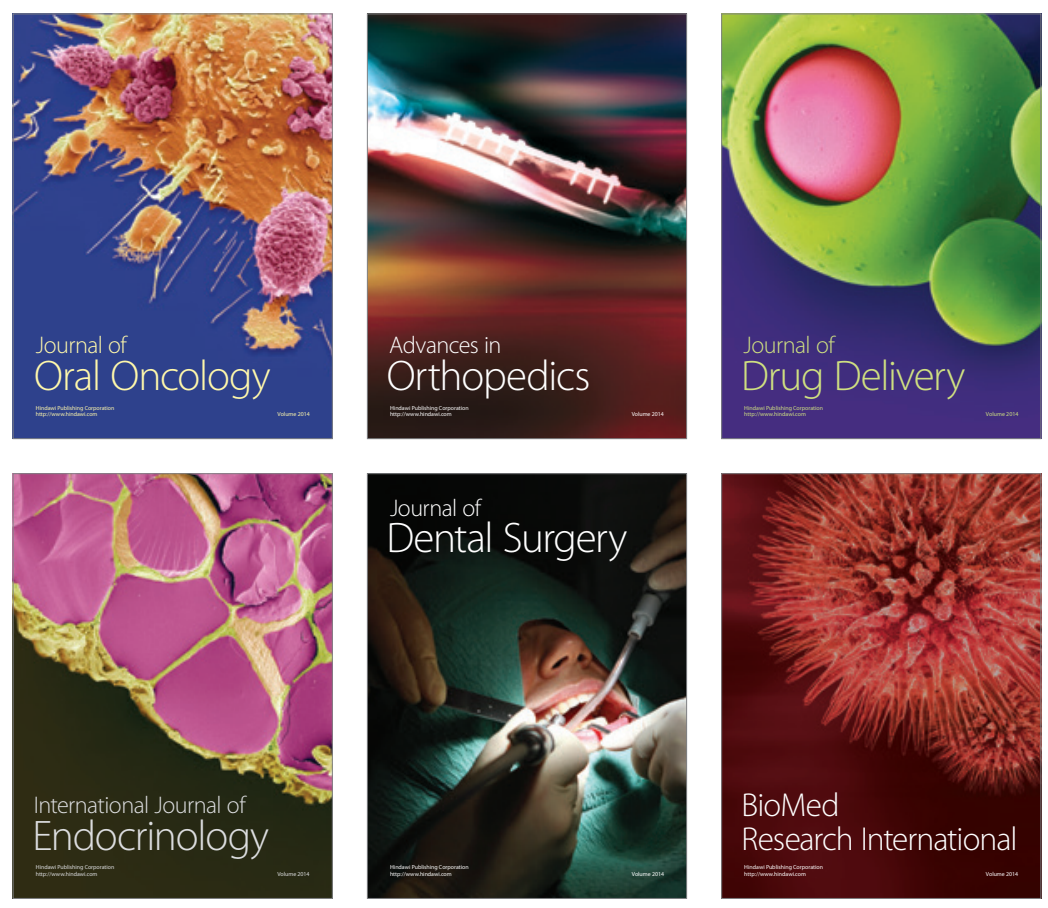

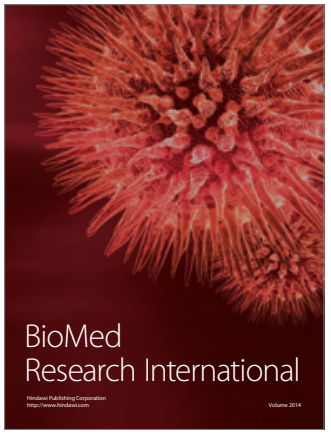

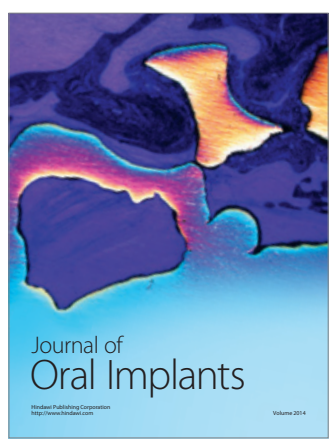
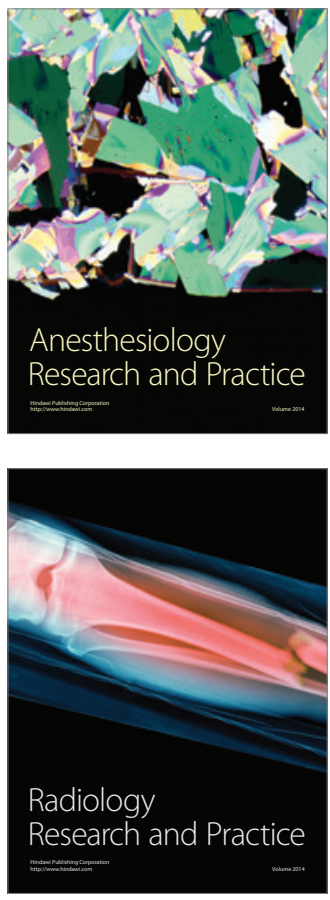